\title{
Public Pedagogy and Representations of Higher Education in Popular Film: New Ground for the Scholarship of Teaching and Learning
}

\section{ABSTRACT}

Constructions of teaching, learning, and the university within popular culture can exert an important influence on public understandings of higher education, including those held by faculty and students. As such, they constitute a rich site of inquiry for the scholarship of teaching and learning. Drawing on the notion of film as 'public pedagogy,' this article analyses representations of higher education within 11 top grossing and/or critically acclaimed films released in 2014. We identify three broad themes across these texts-the purpose of higher education, relationships between students and professors, and the creation of academic identities - and consider the implications and functions of these representational patterns for teaching, learning, and SoTL. Particular attention is given to the difference between the framing of science and arts and humanities disciplines, and to how this might resonate with the contemporary 'crisis of the humanities.'

\section{KEYWORDS}

public pedagogy, popular film, media representations, higher education, instructor-student relationships, academic identities, disciplinary differences

\section{INTRODUCTION}

The year 2014 witnessed the release of eleven popular films that feature higher education. Films such as these are the focus of a growing body of work looking at how popular culture represents teaching and learning. Drawing from theoretical frameworks provided by existing literature, this article examines themes common to representations of higher education within a single year, seeking to understand the ways in which higher education is currently positioned in popular culture and to tease out some of the ramifications of those representational patterns. In so doing, it also seeks to contribute to a growing conversation within the scholarship of teaching and learning about the need to consider a broader array of research questions, methodologies, and sites of learning in SoTL work.

Responding to a call articulated by Bloch-Schulman, Conkling, Linkon, Manarin, and Perkins (2016), our aim in this article is to explore a 'bigger question' that extends beyond 'what works' for student learning in a class or program and resonates with SoTL's political potential. In particular, we investigate how popular films released in 2014 represent teaching, learning, and the university, as we understand such films to perform significant pedagogical work that speaks to the contemporary moment and can, in turn, inform approaches taken to teaching and learning on college and university campuses. 
At the same time, by working with theoretical formulations and methodologies drawn from the humanities, we also seek to contribute to the growing body of humanities-informed SoTL, and thus to participate in ongoing efforts to reaffirm SoTL's methodological and epistemological diversity (e.g., Chick, 2013; Potter \& Wuetherick, 2015; Bloch-Schulman \& Linkon, 2016).

In many ways, the present study also resonates with ideas and conceptions that have been explored extensively in teaching and learning research. For example, a central contention of much pedagogical scholarship is that student and instructor conceptions of teaching, learning, and related constructs intertwine with the ways in which education unfolds in university classrooms. Scholars have documented correlations and connections between educators' views of teaching, learning, and their disciplines and the ways in which they approach their educational roles, and between students' conceptions of learning and knowledge and the approaches they take to studying in particular contexts (e.g., Fanghanel, 2009; Maclellan, 2015; Paakkari, Tynjälä, \& Kannas, 2011; Trigwell \& Prosser, 2014).

While films are certainly not the only factors that might shape such beliefs and perceptions, existing scholarship in film and cultural studies suggests the value of taking seriously their potential influence on understandings of teaching, learning, and the university. Central to this scholarship is the notion that films themselves operate as educators, and film spectators as learners, and that pop culture is thus a critical site of education in modern times (Giroux, 2008; García, 2015). Along these lines, much recent research positions film and television as a form of 'public pedagogy' that functions to educate viewers (including students and instructors) about how education works, what it means, and how students and teachers should behave (Giroux, 2008; Wright \& Sandlin, 2009). In essence, such work suggests that media normalizes societal expectations of education by presenting a narrative construction of these institutions as the contemporary reality, leaving little room to imagine an alternative (García, 2015). Film necessarily constructs and reflects dominant ideologies and social anxieties within a historical context, and in providing a framework through which to view education, influences how audiences approach the education system and construct and navigate their identities as either instructor or student (Giroux, 2008; Gregory, 2007; Vandermeersche, Soetaert, \& Rutten, 2013). Likewise, such texts often take up, feed, and/or help audiences negotiate common suspicions and concerns about teaching, learning, and educators, particularly in relation to the ways educators wield power within the classroom (Benton, 2013; Carens, 2010).

The sense that film legitimizes particular ideological frameworks surrounding educational institutions and thus informs viewers' understanding of the value and process of education resonates interestingly with contemporary concerns about the neoliberalization of higher education, including those expressed within the SoTL literature (e.g., Bloch-Schulman et al., 2016). The contemporary historical moment in the West has been theorized through a variety of different registers, such as the "postmodern" through the lens of culture or "late capitalism" as a signifier of political economy (Jameson, 1991). The ideological framework of this era is often referred to by commentators as "neoliberalism," a particular mode of social and political relations originating in the 1970s and fundamentally defined by "strong private property rights, free markets, and free trade" (Harvey, 2005, p.2). Commentators have extended the implications of neoliberalism beyond the realm of political economy to include hegemonic infiltrations of public spheres (social, cultural, intellectual, etc.) for the purpose of refashioning society in the image of capital (Ibid).

Political theorist Wendy Brown has outlined the effect of what she calls a "neoliberal rationality" on higher education through a few crucial determinations: the defunding of public goods and therefore publicly subsidized education of all kinds; the redefinition of democracy according to economic 
considerations, the terms of which stand at the forefront of politics and therefore reduce the meaning of education to the training of workers (or what she calls "human capital"); and the reconstitution of knowledge and thought to legitimize and/or develop only those forms that contribute to the production and circulation of capital (Brown 2015). In this context, she writes, knowledge "is not sought for developing the capacities of citizens, sustaining culture, knowing the world, or envisioning and crafting different ways of life in common. Rather it is sought for 'positive ROI'-return on investment," a metric which is used in turn to help rank institutions for potential consumers (2015, pp.177-178).

To the extent that film and television texts serve to reflect and perpetuate this neoliberal agenda for education, and thus to fortify hegemonic power structures (García, 2015), they impinge on the work done at colleges and universities in ways that have not yet received much attention within the scholarship of teaching and learning. On one hand, this lack of attention is not surprising; SoTL has focused historically on issues more proximately connected to student learning, often taking up questions about which pedagogical strategies 'work' in particular classes and contexts. Because popular culture has the potential to inform expectations of and approaches to teaching and learning, however, examinations of it offer one way of considering "the way learning is shaped by (and often located in) students' lives outside of the classroom"-an issue Bloch-Schulman and colleagues $(2016$, p.4) position as fundamental to SoTL's ongoing development. While the potential power exerted by and through such texts is not total, not least because audiences have the capacity to push back against the ideologies presented (Wright \& Sandlin, 2009), existing scholarship suggests that the ideas and discourses (re)produced in films have some influence on viewers, and thus demand careful scrutiny. We thus posit that studying filmic representations of higher education constitutes a significant - if not yet commonavenue for SoTL inquiry.

Moreover, even outside the SoTL literature, some gaps remain in the existing research on this subject. Much of the scholarship on representations of teaching and learning focuses on the primary or secondary level, for example, rather than on postsecondary institutions. This article will help fill this gap by focusing specifically on cinematic representations of higher education. Also, most analyses approach this representation by examining closely a few films chosen for their distinctiveness or representativeness, or by looking at a broad range of films from a wide array of genres and time periods. By examining all films related to higher education that were released in 2014 and popular or critically acclaimed in North America, we aimed to take a more structured approach, focusing the analysis and exploring key issues that were present in films released during this year. Scholars already recognize the value in this strategy: Giroux writes that investigating intertextual themes within a specific historical context enables us to move past discussions of meaning and interpretation of an individual film, and instead pursue a deeper understanding of "the social anxieties and assumptions" films take up on a larger scale (2008, p.8).

\section{METHODOLOGY}

For this article, we analysed films from 2014 in which higher education plays a significant role. We chose to look at the year 2014 because it was the most recent and complete year at the beginning of our project, and we saw merit in unpacking the broad patterns and key issues present in modern cinema. Unexpectedly, 2014 also turned out to be a particularly rich year for analysis, with a comparatively large number of films relating to higher education being released. To choose our films, we scrutinised descriptions of the top 100 films at the North American box office on Box Office Mojo (a database that ranks the highest grossing films of a year) as well as all Oscar nominees in performance, direction, and 
best picture categories. We chose these lists because they indicated particularly prominent films of the year, which we felt were the best reflections of what the North American public viewed in theatres and of films held up in public discourse as significant (and thus potentially influential) cultural objects. Of course, other films may well have been popular in other national and regional contexts, but we elected to focus on North America for the present study to reflect our own location and keep our focus manageable. From these lists, we found eleven films in which higher education played a significant role (see the Appendix for a brief summary of each). We then each watched every film and two of us individually took notes on particularly intriguing or pervasive representations of higher education. We discussed our interpretations of the films as a group, shared our notes with each other, and synthesized the notes, a process by which we identified any representations of higher education that we felt were repeated in multiple films in some significant way. Finally, we extracted key themes from our collective notes. We identified three central themes by their prominence in a significant portion of the films: the purpose of higher education, professor-student relationships, and academic identities. Each of the films spoke to at least one of these themes. We then looked at common tendencies in the portrayals of these themes, along with instances where an individual film subverted the tropes other films propagated.

It should be noted that some work has already been done on these themes. For instance, representations of the learning process and the purposes of higher education in films have been the topic of study before (Benton, 2013; Gregory, 2007; Vandermeersche, Soetaert, \& Rutten, 2013). Similarly, common patterns and implications of representations of teachers and students are a frequent topic of analysis (García, 2015; Gregory, 2007; Leuschner, 2006; Stillwagon \& Jelinek, 2015). Our work builds on this existing scholarship by addressing the representational patterns present within a single year, giving detailed insight into how narratives of higher education are framed at one historical moment.

\section{PURPOSE(S) OF HIGHER EDUCATION}

Many of the films we watched explore the various purposes of higher education. The most prominent tension is between viewing postsecondary education as a place to pursue a credential (in line with neoliberal concerns about employability) or as a means of pursuing passion, but there also exists interesting discussion of higher education as a social experience.

\section{The social experience}

The two comedies, Neighbors and 22 Jump Street, suggest higher education is predominantly a social experience. Reflecting a pattern common to the genre, the student characters in both comedies are primarily occupied with drugs and sex, giving at best passing attention to attending class. In Neighbors, for example, the only character who frequents his courses is positioned as doing so simply so the fraternity can acquire school equipment. In 22 Jump Street, the professors in the class sequences are desperate for their students' attention, and the fact that one of the protagonists learns something in class is an ongoing joke. In this way, these comedies turn the idea of learning in university into a punchline, ridiculing the educational aspect of higher education. Moreover, the films often present the educational aspect of higher education in conflict with the social lives of the students when characters find they have done poorly in school because of their focus on socialising (Neighbors) or when they must do schoolwork instead of something they enjoy (22 Jump Street). These presentations inevitably frame the educational system, and instructors in particular, as antagonists to the students' social life and their ability to enjoy higher education. 


\section{Credentialism}

The films Neighbors, Still Alice, God's Not Dead, and The Gambler all allude to the growing credentialism of higher education in the contemporary moment. In Neighbors, one of the few references to education occurs when a protagonist is asked for his GPA at a job fair, implying the purpose of higher education is to acquire the grades necessary to get a job. This film is unique amongst those analysed in its lack of nuance on this front, however, with all the other films challenging this vision of education to some extent. In Still Alice, the daughter who refuses to attend college as a backup plan is ultimately valorized because she is the person who cares for her mother once her mother becomes ill. Similarly, the plot of God's Not Dead revolves around a student who refuses to agree with his professor's opinions despite many other characters pressuring the student to give in and get the grade. In The Gambler, the protagonist is frustrated by students who are only taking his class to earn a credit.

This presentation and corresponding rejection of credentialism suggests an interesting ambivalence in perceptions of the purpose of higher education: the films acknowledge the prevalence of the belief that higher education is about credentials and then (minimally) challenge it, suggesting there is (or should be) more to these institutions than getting a credit or a degree. Nevertheless, some scholars argue challenges offered in films are usually superficial-Hollywood's focus on the individual means that there is little consideration of institutionalised problems since most cinematic challenges are overcome by individuals (Giroux, 2008; Seamus \& Mackler, 2015). Hence, while individual students or faculty may be presented as progressive "they seldom mount a direct challenge to dominant ideology" (Dalton, 2006, p.31). In God's Not Dead, for instance, the protagonist inspires supporting characters to challenge Professor Radisson as he does himself, but all of the characters who pressure the students to submit to Professor Radisson's beliefs (most of whom are parental figures) still value credentials by the end of the film and have chosen to stop speaking with the 'rebellious' students. This necessarily means that, while the characters' rejection of credentialism is celebrated through the protagonist's intellectual triumph over the professor, the widespread expectations of credentialism remain since none of these characters or structures are reformed. This kind of half-hearted critique of credentialism is prevalent throughout many of the films.

\section{Pursuing your passion}

The common alternative to credentialism in these films is a focus on developing passion. The passion the protagonists pursue in higher education is often artistic, such as in Boyhood (photography), If I Stay (music: cello), and Whiplash (music: drums). Passion as a purpose of higher education is also often challenged in the films, though not as overtly as credentialism. For example, in If I Stay, the protagonist's passion for music draws her away from her passion for her boyfriend, jeopardizing the relationship that is central to the film and that Hollywood generic conventions encourage us to endorse. In Whiplash, the severe nature of the pedagogy represented and the protagonist's increasing rudeness suggest his reckless pursuit of his passion is problematic. Conversely, in Still Alice, as noted above, one daughter rejects the possibility of going to drama school to further her passion for acting, and is valorized by the film through her care for her mother. Thus, the films that are about artists pursuing their passion in university tend to depict this pursuit negatively while the film that shows an artist rejecting this option presents this choice positively. These patterns are indicative of tension regarding whether higher education institutions are the right place to pursue artistic passion. By contrast, in films focusing on faculty experiences, the academics are typically passionate about scientific disciplines, and this passion is usually subtle and not destructive. In The Imitation Game and The Theory of Everything, for example, 
the protagonists' passion for their work defines who they are, creates knowledge celebrated in intellectual circles, and (in the case of Alan Turing) literally saves lives. For a scientific academic, higher education is often presented as the correct context to pursue one's passion.

\section{PROFESSOR-STUDENT RELATIONSHIPS}

A second theme that is prominent in many of the texts studied is the issue of professor-student relationships. Insofar as these relationships speak particularly clearly to views of the pedagogical work of higher education institutions, they are perhaps especially relevant to SoTL scholars. Interestingly, while some previous research unpacks a range of student-teacher relationships and stereotypes within popular culture (e.g., Gregory, 2007; Vandermeersche, Soetaert, \& Rutten, 2013), the present set of films is tilted in favour of critical or ambivalent representations of faculty-student interactions, often positioning faculty as abusive, manipulative, or exploitative-particularly within humanities disciplines (Carens, 2010).

\section{Romantic relationships}

Romantic relationships between professors and students are common to many of the texts studied, as a recurring element that seems to challenge societal norms and values and question the extent to which teaching and learning are the primary foci of teacher-student encounters in the university. As Carens (2010, p.9) has noted of films focusing on English professors, these relationships are often founded on representations of faculty as "dangerously seductive figure [s]" who are able to control and master the 'subjective' content of their fields. On this note, many of these texts portray faculty as intriguing and expert lecturers who ultimately abuse their appeal to engage students in morally questionable romantic relationships.

Both God's Not Dead and Boyhood, for example, present abusive manifestations of such relationships. God's Not Dead highlights the problematic power dynamics that shape faculty-student romance through its portrayal of the relationship between a philosophy professor and one of his former students, offering a critique of faculty abuse of authority that is striking in its lack of nuance. The professor is continually rude and abusive to his ex-student girlfriend, dismissive of her opinions, and undercuts her intelligence ad nauseum. He is also controlling to a fault, and demonstrates this in one instance through his refusal to date this ex-student unless she is willing and able to ace a midterm. While less extreme in its portrayal, Boyhood also suggests that faculty-student romance is both common and problematic. The central mother character's marriage to her passionate psychology professor is complicated by the professor's later alcoholism, while her second marriage to one of her own impressed students later in her career also ends in abuse, although in this case the roles of faculty as abuser and student as abused are inverted.

In addition, texts including God's Not Dead and The Gambler almost caricaturize these relationships and their socially unacceptable status; the relationships are recognized as inappropriate but this notion is trivialized or undercut. The male professors in both these texts actively jest about the fact that their female students could potentially get them fired, suggesting their relationships are informally acceptable even if institutionally discouraged. This viewpoint obscures or disregards the reasons such relationships are problematic, and the consequences of violating the established principles are seen as an inconvenience at best. In fact, in The Gambler, the relationship is presented as one of the sole positive occurrences in the protagonist's life, though—in a moment of ambivalence- he is shown to be troubled by both his student's fanaticism regarding his research and the exploitation inherent to their relationship 
more generally. At such moments, the texts studied depict morally questionable relationships in a way that simultaneously acknowledges and dilutes the significance of the exploitation involved, while implying that these arrangements are ubiquitous at the institutions that forbid them.

\section{Highly abusive relationships}

We also identified multiple instances in which non-romantic faculty-student relationships were shown to be abusive. The instances of such abuse in the texts studied range from the verbal to the physical, with implications for how professors and their pedagogical methods are represented in popular culture.

Alongside its depiction of a faculty-student romantic relationship, God's Not Dead also presents its central professor character as consumed with humiliating a student in his class. Professor Radisson is continually depicted in the text as single-minded and overtly dismissive of any notion of student empowerment, and when the central character dares defy him, Radisson resorts to personally insulting this student in front of his peers and even threatening the student's future career. Whiplash likewise deals with a music professor who regularly abuses his students in myriad ways. Many of these students are shown to tolerate such abuse as it is viewed as a stepping-stone to a career in the field, with the implication that such abusive behaviour is a normalized phenomenon. The instructor, Fletcher, is an intense presence at rehearsals, continuously humiliating his students by hurling homophobic and other demeaning insults (as well as objects) at students as a matter of self-conscious, militaristic discipline. He also attempts to gain more insight into his students' personal lives in order to leverage this information for the explicit purpose of psychological manipulation. The text demonstrates the destructive capacity of such abuse, featuring extended sequences that image the protagonist injuring himself as he struggles to meet Fletcher's standards. Although the protagonist, Neiman, almost dies as a result of the effects of Fletcher's pedagogy, the text interestingly makes an attempt to pitch such an approach as potentially valid - it ends with both professor and student reaching a mutual goal of impressive, 'genius-level' performance as a result of Fletcher's destructive method. Finally, unlike the Professor Radisson character in God's Not Dead, Fletcher does not mobilize his position to exploit female students. Indeed, his ensemble for the majority of the text does not feature any female students at all (and his later ensemble features just one), rendering his militaristic approach sexist, but foregoing common patterns of heterosexual romantic exploitation.

The abusive depiction of professor-student relationships seems to be most common when the text is presented from the perspective of the student. This illustrates concerns about the destructive capacity of a power dynamic being pushed to the brink, as the circumstances in play are seemingly always in the control of the professor-the only power in the room. The professors who engage in abusive practices in the classroom are, on the surface, motivated by a desire to push their students to perform at their best, rationalizing their abusive behaviour to this end. They are also celebrated for the results of such destructive pedagogy to some extent, as they are-once again-respected in their fields and are viewed by their students as avenues to success. What is evident from the texts studied is a lack of support for students navigating such pedagogies and power differentials, highlighted in Whiplash as Neiman's only support in the college is a counselor (who identifies Fletcher's abusive practices as a known issue in the institution). The counselor encourages Neiman to anonymously report Fletcher's behaviour, and such an intervention is depicted as the only way a student can possibly hold power accountable. The texts thus imply that abusive behaviour is tolerated in higher education due to an emphasis on 'tangible results' at any cost, de-legitimizing a pedagogy that emphasizes respect for 
students and suggesting compelling uncertainties about teaching and learning in universities within an outcomes-focused culture.

An interesting exception to the focus on the humanities in relation to problematic relationships can be found in Big Hero 6. In this film, the robotics professor leverages his capacity as a mentor and father figure against Hiro, the protagonist, to gain access to his innovative talent. Claiming to protect Hiro's genius and its fruitions, as well as his future from the exploitation of corporate interests, the professor is eventually revealed to be engaging in exploitation himself-stealing and mobilizing Hiro's inventions and adapting them for militaristic purposes to fuel an act of vengeance. The professor also commits acts of physical violence against his former students in the process, literally engaging them in battle in ways that transform the knowledge developed in their shared lab into weapons wielded against one another. Despite the fact that the text is marketed as an animated children's action film, it thus evokes the normalization of militarism and violence in the neoliberal academy, but repositions this as a personalized conflict between a professor-villain and his students. The text can be interpreted as a commentary on the role of professors as mentors, and it is evident that this professor's approach to the role is exploitative and unethical, even if it is ultimately explained by reference to a personal loss in his life. In this respect, the film resonates with the suspicions of the professoriate evoked by the texts focusing on inappropriate romantic relationships.

\section{ACADEMIC IDENTITIES}

A third broad theme found in the corpus of texts focuses on the question of faculty identities, taking up and inflecting conceptions of "what it means to be an academic" in higher education (Bennett et al., 2016, p.218). In recent years, a range of scholars have explored the ways in which higher education faculty understand and construct themselves and their roles (e.g., Fanghanel, 2012), often considering the extent to which traditional understandings of the professoriate are under pressure from increasing neoliberalization and managerialism (Degn, 2015; Sutton, 2015). The films examined thus enter interestingly into a conversation about the definition and contours of academic roles at a moment of uncertainty and contestation. One particular sub-theme, which was especially prominent in the texts, is discussed below.

\section{Research/creation vs. teaching}

Aligning strongly with a range of work that emphasizes the centrality of research, discovery, and the discipline to faculty conceptions of self (e.g., Henkel, 2005), many of the films examined positioned their faculty characters as scholars advancing knowledge and practice within a discipline above all else. This is especially clear in films such as The Imitation Game and The Theory of Everything, both of which centre on the figure of the (male) 'genius scientist' whose work breaks major intellectual boundaries. Indeed, neither Turing nor Hawking is ever shown teaching a class, while both films devote laborious attention to images of the central characters engaged in research activities. While less prominent, this emphasis on disciplinary scholarship can also been seen in Still Alice, in which the central character is renowned for her linguistics research and her husband (also a faculty member) largely discusses time spent in the lab rather than in the classroom. In contrast, in Big Hero 6, the dichotomy between research and teaching is blurred somewhat, insofar as the educational experience itself is framed as a research opportunity under the supervision of a skilled engineering scholar. The central position of research, however, is nonetheless maintained.

In other films from the set, including Whiplash and The Gambler, academics are shown 
primarily in the context of their teaching, but are simultaneously positioned as highly disillusioned and dissatisfied with their work. In Whiplash, for instance, we do not see Fletcher himself perform as a musician until after he has been forcibly removed from his faculty position, and - even then - his focus remains arguably on his unfinished and unhealthy teacher-student relationship with Neiman. Significantly, a connection to the discipline is still a central component of this representational pattern, insofar as much of the represented discontent is ostensibly connected to the challenges of engaging students meaningfully in the complexities of the field they are studying. In spite of Fletcher's intense focus on the teaching component of his role, for example, he consistently manifests disgust with his students and their apparent inability to meet his exacting standards, ultimately arguing that the neoliberal focus on student satisfaction has undercut his ability to challenge his students such that they develop productively into 'actual' artists.

Similarly, Jim Bennett in The Gambler is frequently shown teaching, but-like Fletcher-he rarely seems fulfilled by this work. He complains about disengaged students who are there simply to get credits and about being pressured to pass athletes so they can remain on varsity teams, and disdains the very notion of teaching by arguing that genius is the only criterion of value and that it cannot, by definition, be taught. To some extent, Bennett's disenchantment with teaching seems to be bred by his failure to meet his own standards of greatness as an author and scholar in his field. Because he does not possess the 'genius' he advocates, he claims, he is stuck "pretend[ing] to teach" while his students "pretend to learn." In this respect, his disillusionment again affirms the perceived centrality of scholarship and creation within academic identity construction; when the ability to function centrally as a scholar is undermined, the film suggests, one is 'left with' teaching, which in turn is shown as fruitless and deadening in a context focused on surface credentialism.

On one hand, such apparent frustrations with teaching might be seen to offer a rich frame through which faculty audiences might negotiate pressures on traditional conceptions of academic identity. By valuing 'ground-breaking' research and critiquing the frustrating nature of education in a system which discourages challenge and lowers standards, this sub-set of films might be said to offer a partial validation of faculty concerns about contemporary pressures on established professorial roles. On the other hand, it bears mentioning that the films that bring up the purported dissatisfactions of teaching in the neoliberal university are typically rather critical of the faculty characters they contain, throwing some doubt on this critique by implying that the individuals articulating it are arrogant, sadistic, manipulative, and/or out of touch. To some extent, then, these films as a group might be said to rearticulate the value of research to academic identities, while simultaneously evoking and undercutting challenges attached to the teaching components of faculty roles. In this respect, they are particularly interesting to consider in relation to SoTL, as they offer comparatively little consideration of the possibility of a meaningful academic identity focused (at least in part) on teaching in the neoliberal university.

\section{DISCUSSION}

This study opens the door for further SoTL inquiry. For instance, many scholars have called for more work to be done regarding spectator response to popular representations (Wright \& Sandlin, 2009). In the context of SoTL, a study of faculty and student response to the themes we explore in this article would offer valuable insight into how viewers receive, interpret, and internalize the representations of higher education offered in popular films, and how they might take up or respond to such representations in their work on college and university campuses. Insofar as our focus here is on 
films that were popular at the North American box office (all of which are themselves American-made), further consideration of both the resonance and function of these films in other national contexts and of the representational patterns at work in non-American films is needed. Similarly, comparisons might be made to texts produced at different historical moments, and further attention could be paid to how questions of genre shape representation and effect. Finally, some of the films released in 2014 offer particularly complex and nuanced depictions of higher education (such as Big Hero 6); a focused analysis of one of these films would allow for more detailed examination of how higher education is addressed cinematically than is possible here (including, importantly, more attention to choices of film form). Nonetheless, like other work sketching broad patterns (e.g., Gregory, 2007), the present analysis teases out a number of significant ideas that contribute to understanding how filmic representations take up and help shape perceptions of higher education in the contemporary moment within North America. In so doing, it generates potential key areas of inquiry on which teaching and learning scholars might focus going forward.

The three themes identified here do not exist in isolation, but instead interact in interesting and complex ways. Taken as a set, they tend to suggest a degree of ambivalence or uncertainty about teaching, learning, and faculty in higher education contexts. For instance, both credentialism and passion are criticized as purposes of higher education, implying a currently felt need to re-evaluate the benefit of these institutions as places where meaningful learning occurs, and offering a range of (sometimes contradictory) responses to the neoliberal mindset described by Brown. Similarly, the relations between professors and students are often positioned as exploitative and abusive, signalling and reproducing suspicion about the potential for meaningful pedagogical practice in colleges and universities. This tendency to criticise higher education is also found in the films' portrayal of academic identities. Some films suggest that research is central to professorial roles, and that teaching (which is frequently positioned as a separate endeavour) is often dissatisfying and/or lacklustre in the neoliberal university. However, this focus on research is largely validated only when the scholarship is seen as 'ground-breaking,' and the comparatively negative framing of teaching-focused faculty undercuts to some extent both the positive potential of teaching and the specific concerns these characters articulate. Of particular interest to SoTL scholars, the notion of students and faculty working together to advance understanding or push meaningfully against neoliberal constructions, an idea increasingly common to discourse about students as partners in higher education (e.g., Healey, Flint, \& Harrington, 2016; CookSather \& Abbot, 2016), is comparatively absent. Faculty and students are framed as adversaries, somewhat unsettling romantic partners, or distant parties of minimal concern to one another, and pedagogies that might be seen as effective or research informed are few and far between. These representational patterns have the capacity to influence approaches to teaching and learning on our campuses.

Interestingly, the texts studied also offer a glimpse into socially mediated perspectives on academic disciplines in the neoliberal West-perspectives that reflect popular conceptions of the divide between the arts and sciences, shape discourse, and have implications for the governance of the modern university more broadly. In particular, the sciences tend to be portrayed in more favourable terms: as a site in which 'ground-breaking scholarship' occurs with minimal critique (Still Alice, The Imitation Game, The Theory of Everything), as a context in which passionate engagement can be pursued and developed meaningfully within university structures and systems (Big Hero 6, The Theory of Everything), and as a division of the academy wherein dissatisfying and manipulative teaching is less common (though not absent--as seen in Big Hero 6). In comparison, the arts are often portrayed in a 
negative light, with a strong focus on unfulfilling and problematic teaching (The Gambler, Whiplash); with the relevant instructors often portrayed as dissatisfied, neurotic, and self-obsessed (The Gambler, God's Not Dead, Whiplash); and with the notion of pursuing one's passion or developing intellectually often undercut by credentialism, suspicion, or uncertainty (The Gambler, If I Stay, Whiplash). Of course, exceptions to these rules exist and many of the films offer additional nuance and complexity atop these broad patterns. Nevertheless, the patterns themselves remain.

This view of arts and humanities disciplines resonates with Carens' observation that, since the late 1970s, English professors have been depicted in films and television as seductive and attractive figures that nonetheless abuse their authority and are frequently revealed as impostors hiding behind a veil of falsely constructed expertise. This pattern, Carens argues, "reveals a widespread ambivalence, a fascination intermingled with distrust" connected to the discipline's status as a field without clear, 'correct' answers (2010, p.10). The present analysis indicates this observation could be extended to contemporary popular representations of humanities disciplines in higher education more generally. Films such as those examined here thus might be seen to help explain and reproduce a bias toward the sciences in a technologically dominant era-including, potentially, amongst students.

The comparatively negative or ambivalent framing of arts and humanities disciplines across this corpus of texts also resonates interestingly with the contemporary 'crisis of the humanities' in the neoliberal university (Barnett, 2014). While all disciplines and sectors of the academy are affected by neoliberal discourse, scholars such as Brown (2015) have noted that liberal arts disciplines are particularly at risk in this context. She writes:

... cultural values spurn [liberal arts education], capital is not interested in it, debt-burdened families anxious about the future do not demand it, neoliberal rationality does not index it, and, of course, states no longer invest in it. According to popular wisdom, the liberal arts are passé, the protected ivory tower is an expensive and outmoded relic, and the more the university remakes itself through and for the market, the better off everyone-except overpaid, underworked tenured faculty-will be (2015, pp. 180-181).

Indeed, as universities are increasingly assessed in terms of their capacity to develop both 'productive,' employable graduates and innovative, marketable scholarship (Cote \& Allahar, 2011), the supposed value of the humanities (as one subset of the liberal arts) has come under considerable scrutiny (Belfiore, 2015; Benneworth, 2015). Whereas many scholars have suggested the need for a nuanced view that pushes back against this framing of the university and the role of the humanities within it, while - in some cases - also considering the necessity of evolution and reform (Barnett, 2014; Evans, 2014; McArthur, 2011), such nuance is largely absent from the films considered here as a set.

Instead, as examples of public pedagogy, these films take up and largely reproduce existing uncertainty and skepticism about the value of humanities teaching and research in the contemporary, neoliberal moment. In this, they resemble other popular culture texts that have been read to contribute to the neoliberal agenda in relation to other educational sectors (e.g., García, 2015). Nevertheless, by raising issues such as the frustrations of teaching in contexts focused on student satisfaction and the dangers of credentialism, even in circumscribed ways, some of the films might be said to point toward the potential fissures and tensions within this ideological agenda. With this in mind, further attention should be paid to the ways in which the broad themes described in this article are played out and inflected in individual popular films and taken up by actual spectators, including faculty and students. By 
unpacking the particular 'lessons' such texts deploy, teachers, learners, and SoTL scholars can more consciously intervene in the pedagogical activities of pop culture, responding to Giroux's call to view 'film as a site of critique, understanding, and struggle' in the process (2004, p.126).

Katelyn Johnstone is a student in the Arts \& Science program at McMaster University and a student partner at McMaster's Paul $R$. MacPherson Institute for Leadership, Innovation, and Excellence in Teaching.

Elizabeth Marquis is an Assistant Professor in the Arts \& Science program at McMaster University and Associate Director (Research) at McMaster's Paul R. MacPherson Institute for Leadership, Innovation, and Excellence in Teaching.

Varun Puri is a graduate of the Arts \& Science program at McMaster University and a student partner at McMaster's Paul $R$. MacPherson Institute for Leadership, Innovation, and Excellence in Teaching.

\section{REFERENCES}

Barnett, R. (2014). Imagining the humanities-amid the inhuman. Arts \& Humanities in Higher Education, 13(12), 42-53.

Belfiore, E. (2015). 'Impact,' 'value,' and 'bad economics': Making sense of the problem of value in the arts and humanities. Arts \& Humanities in Higher Education, 14(1): 95-110.

Bennett, R., Hobson, J., Jones, A., Martin-Lynch, P., Scutt, C., Strehlow, K., \& Veitch, S. (2016). Being chimaera: A monstrous identity for SoTL academics. Higher Education Research and Development, 35(2), 217-228.

Benneworth, P. (2015). Putting impact into context: The Janus face of the public value of arts and humanities research. Arts \& Humanities in Higher Education, 14(1), 3-8.

Benton, S. (2013). Two heads are better than one (and three are better than two): Challenging the individualist ethos of the educator-hero film. Journal of Popular Film and Television, 41(2), 98-108.

Bloch-Schulman, S., \& Linkon, S.L. (2016). Scholarship of teaching and learning in the arts and humanities: Moving the conversation forward. Teaching \& Learning Inquiry, 4(1), 1-3.

Bloch-Schulman, S., Wharton Conkling, S., Linkon, S.L., Manarin, K., \& Perkins, K. (2016). Asking bigger questions: An invitation to further conversation. Teaching \& Learning Inquiry, 4(1), 1-7.

Brown, W. (2015). Undoing the Demos: Neoliberalism's Stealth Revolution. New York: Zone Books.

Carens, T.L. (2010). Serpents in the garden: English professors in contemporary film and television. College English, 73(1), 9-27.

Chick, N.L. (2013). Difference, privilege, and power in the scholarship of teaching and learning: The value of Humanities SoTL. In K. McKinney (ed.), The Scholarship of Teaching and Learning in and Across the Disciplines (pp. 15-33). Bloomington: Indiana UP.

Cook-Sather, A., \& Abbot, S. (2016). Translating partnerships: How faculty-student collaboration in explorations of teaching and learning can transform perceptions, terms, and selves. Teaching \& Learning Inquiry, $4(2), 1-14$.

Cote, J. \& Allahar, A.L. (2011). Lowering Higher Education: The Rise of Corporate Universities and the Fall of Liberal Education. Toronto: University of Toronto Press.

Dalton, M.M. (2006). Revising the Hollywood curriculum. Journal of Curriculum and Pedagogy, 3(2), 29-34.

Degn, L. (2015). Identity constructions and sensemaking in higher education - A case study of Danish higher education department heads. Studies in Higher Education, 40(7), 1179-1193.

Evans, M. (2014). Liberal values at a time of neo-liberalism. Arts \& Humanities in Higher Education, 13(1-2), 17-23.

Fanghanel, J. (2012). Being an Academic. London: Routledge.

Fanghanel, J. (2009). The role of ideology in shaping academics' conceptions of their discipline. Teaching in Higher Education, 14(5), 565-577.

García, J. (2015). Learning from bad teachers: The neoliberal agenda for education in popular media. Critical Education, 6(13). http://ices.library.ubc.ca/index.php/criticaled/article/view/184935

Giroux, H. (2004). Pedagogy, film, and the responsibility of intellectuals: A response. Cinema Journal, 43(2), 119127.

Giroux, H. (2008). Hollywood film as public pedagogy: Education in the crossfire. Afterimage, 35(5), 7-13.

36 Johnstone, K., Marquis, E., \& Puri V. (2018). Public pedagogy and representations of higher education in popular film: New ground for the scholarship of teaching and learning. Teaching \& Learning Inquiry, 6(1). http://dx.doi.org/10.20343/teachlearninqu.6.1.4 
Gregory, M. (2007). Real teaching and real learning vs narrative myths about education. Arts \& Humanities in Higher Education, 6(1), 7-27.

Harvey, D. (2005). A Brief History of Neoliberalism. New York: Oxford University Press.

Healey, M., Flint, A., \& Harrington, K. (2016). Students as partners: Reflections on a conceptual model. Teaching \& Learning Inquiry, 4(2), 1-13.

Henkel, M. (2005). Academic identity and autonomy in a changing policy environment. Higher Education, 49(12), 155-176.

Jameson, F. (1991). Postmodernism, or, the Cultural Logic of Late Capitalism. London: Verso.

Leuschner, E. (2006). Body damage: Dis-figuring the academic in academic fiction. Review of Education, Pedagogy, and Cultural Studies, 28(3-4), 339-354.

Maclellan, E. (2015). Updating understandings of 'teaching': Taking account of learners' and teachers' beliefs. Teaching in Higher Education, 20(2), 171-182.

McArthur, J. (2011). Reconsidering the social and economic purposes of higher education. Higher Education Research \& Development, 306), 737-749.

Paakkari, L., Tynjälä, P., \& Kannas, L. (2011). Critical aspects of student teachers' conceptions of learning. Learning and Instruction, 21, 705-714.

Potter, M.K. \& Wuetherick, B. (2015). Who is represented in the teaching commons? SoTL through the lenses of the arts and humanities. Canadian Journal for the Scholarship of Teaching \& Learning, 6(2), page

Seamus, M. \& Mackler, S. (2015). The existential significance of cinema in educational administration. Journal of Aesthetic Education, 49(2), 1-19.

Stillwagon, J. \& Jelinek, D. (2015). A note on the scandals: The role of filmic fantasy in reproducing teaching and its transgressions. In T.E. Lewis \& M.J. Laverty (eds.), Art's Teachings, Teaching's Art: Philosophical, Critical and Educational Musings (pp.89-103). New York: Springer.

Sutton, P. (2015). A paradoxical academic identity: Fate, utopia and critical hope. Teaching in Higher Education, 20(1), 37-47.

Trigwell, K. \& Prosser, M. (2014). Qualitative variation in constructive alignment in curriculum design. Higher Education, 67, 141-154.

Vandermeersche, G., Soetaert, R. \& Rutten, K. (2013). "Shall I tell you what is wrong with Hector as a teacher?": The History Boys, stereotypes of popular and high culture, and teacher education. Journal of Popular Film and Television, 41(2), 88-97.

Wright, R.R. \& Sandlin, J.A. (2009). Cult TV, hip hop, shape-shifters, and vampire slayers: A review of the literature at the intersection of adult education and popular culture. Adult Education Quarterly, 59(2), 118-141.

Copyright for the content of articles published in Teaching \& Learning Inquiryresides with the authors, and copyright for the publication layout resides with the journal. These copyright holders have agreed that this article should be available on open access under a Creative Commons Attribution License 4.0 International (https://creativecommons.org/licenses/by/4.0). The only constraint on reproduction and distribution, and the only role for copyright in this domain, should be to give authors control over the integrity of their work and the right to be properly acknowledged and cited, and to cite Teaching \& Learning Inquiry as the original place of publication. Readers are free to share these materials-as long as appropriate credit is given, a link to the license is provided, and any changes are indicated. 